\title{
Oral and Oropharyngeal Reconstruction with a Free Flap
}

\author{
Woo Shik Jeong, \\ Tae Suk Oh \\ Department of Plastic and Reconstructive \\ Surgery, Seoul Asan Medical Center, \\ University of Ulsan College of Medicine, \\ Seoul, Korea
}

No potential conflict of interest relevant to this article was reported.

\begin{abstract}
Extensive surgical resection of the aerodigestive track can result in a large and complex defect of the oropharynx, which represents a significant reconstructive challenge for the plastic surgery. Development of microsurgical techniques has allowed for free flap reconstruction of oropharyngeal defects, with superior outcomes as well as decreases in postoperative complications. The reconstructive goals for oral and oropharyngeal defects are to restore the anatomy, to maintain continuity of the intraoral surface and oropharynx, to protect vital structures such as carotid arteries, to cover exposed portions of internal organs in preparation for adjuvant radiation, and to preserve complex functions of the oral cavity and oropharynx. Oral and oropharyngeal cancers should be treated with consideration of functional recovery. Multidisciplinary treatment strategies are necessary for maximizing disease control and preserving the natural form and function of the oropharynx.
\end{abstract}

Keywords: Oral reconstruction / Oropharyngeal reconstruction / Free flap / Head and neck cancer

\section{INTRODUCTION}

The incidence of oral cavity cancer and oropharyngeal cancer is increasing in Korea, with 11,792 cases occurring between 2008 and 2012 and 7,484 cases occurring between 1996 and 2000. In the year 2012, oral cavity and oropharyngeal cancer was diagnosed in 2913 patients, whose 5-year survival rate was at $62.2 \%$ (survival rate for all cancers combined at approximately 68\%) [1].

The oral cavity space extends from the skin-vermilion junctions of the lips to the junction of the hard and soft palates above and to the line of circumvallate papillae below to include the lip, anterior two-thirds of the tongue, buccal mucosa, floor of the mouth, upper and lower gingiva, retromolar trigone, and hard

Correspondence: Tae Suk Oh

Department of Plastic and Reconstructive Surgery, Seoul Asan Medical Center, University of Ulsan College of Medicine, 88 Olympic-ro 43-gil, Songpa-gu, Seoul 05505, Korea

E-mail: tasuko@amc.seoul.kr

Received January 27, 2016 / Revised February 4, 2016 / Accepted February 11, 2016 palate. The oropharyngeal space is located between the soft palate superiorly and the hyoid bone inferiorly and is divided into the base of the tongue, tonsillar region, soft palate, uvula, and posterior and lateral pharyngeal walls [2].

In addition to tobacco and alcohol use as major risk factors, the development of oral and oropharyngeal cancers (OPCs) have been shown to correlate with ultraviolet radiation, human papillomavirus (HPV), immunosuppression, the areca nut, and lower socioeconomic status. While consumption and alcohol and tobacco products have been decreasing or remains constant, the incidence of OPC continues to increase because of the increasing incidence of the HPV-associated tumors, which is prevalent in young adults with minimal tobacco and alcohol exposure [3].

\section{ORAL CAVITY CANCER}

The oral cavity is a common site of malignancy worldwide and is especially common in developing countries [4,5]. Squamous cell 
carcinoma represents the most common histologic type, with tobacco and alcohol use being the primary etiologic factors [6]. Although oral cancer can be detected early, patients frequently present in advanced stages. The treatment of choice is surgical resection with or without postoperative adjuvant chemotherapy and/or radiotherapy. Advancements in surgical resection and the addition of adjuvant therapies have led to improved survival rates over the past decade [7]. This success in multidisciplinary approach stems from basic strategies to maximize disease control and to preserve the natural form and functions of the oral cavity.

\section{OROPHARYNGEAL CANCER}

Located posterior to the oral cavity and between the nasopharynx and larynx, the oropharynx aids in critical functions such as swallowing and maintaining patent airway. The oropharynx is also crucial for speech because of the need for mobility and pliability and because of proximity of the base of tongue to the larynx. The oropharynx consist of the soft palate, posterior and lateral pharyngeal walls, faucial arches, tonsillar fossa, and the base of tongue. Anatomically, the non-restraining soft tissue boundaries as well as the rich lymphatic supply allow for escape of malignant cells, which results in most patients presenting with advanced disease (stage III or IV) [5]. Traditionally, the oropharynx was considered to be difficult to access by surgical means, and refinement of radiation therapy and the use of combination chemoradiotherapy have made nonsurgical approaches the standard practice [8]. However, recent advancements in minimally invasive techniques have rekindled interest in surgical management of oropharyngeal cancers.

\section{TREATMENT OF OROPHARYNGEAL CANCERS}

Oropharyngeal cancers are generally treated by a combination of surgery, radiotherapy, and/or chemotherapy. The treatment protocol is dependent on tumor size, site of occurrence, staging, the medical and nutritional status of the patient, and patient preference for treatment modality [9]. Both the tumor and its treatment can interfere with speech and swallowing function, which can subsequently interfere with quality of life and ability to work. As such, the treatment of oropharyngeal cancers should aim to preserve function and to minimize complications, in addition to curing the disease itself. A comprehensive multidisciplinary team should include the coordination of oncologic and plastic surgeons, medical oncologist, radiation oncologist, oral health care providers, nutritionist, nurse specialist, and speech pathologist.

\section{FREE FLAP RECONSTRUCTION OF ORAL AND OROPHARYNGEAL DEFECTS}

Extensive surgical resection of the aerodigestive track can result in a large and complex defect of the oropharynx, which represents a significant reconstructive challenge for the plastic surgery. Development of microsurgical techniques has allowed for free flap reconstruction of oropharyngeal defects, with superior outcomes as well as decreases in postoperative complications, as compared to non-free flap reconstructive options [10]. With regard to the type of free flaps used in oropharyngeal reconstruction, fasciocutenous free flaps and enteric free flaps such as jejunum are widely used. However, enteric free flaps lead to frequent dysphagia necessitating laparotomy [11]. Fasciocutaneous flaps include the radial forearm free flap and anterolateral thigh free flap, and these flaps are associated with excellent functional outcomes and low donorsite morbidity (Fig. 1).

\section{FUNCTIONAL OUTCOMES FOLLOWING COMPLEX OROPHARYNGEAL RECON- STRUCTION}

The reconstructive goals for oral and oropharyngeal defects are to restore the anatomy, to maintain continuity of the intraoral surface and oropharynx, to protect vital structures such as carotid arteries, to cover exposed portions of internal organs in preparation for adjuvant radiation, and to preserve complex functions of the oral cavity and oropharynx [12-14]. With the development of microsurgical techniques, free flaps has become the most popular choice for reconstruction of oral and oropharyngeal defects in 

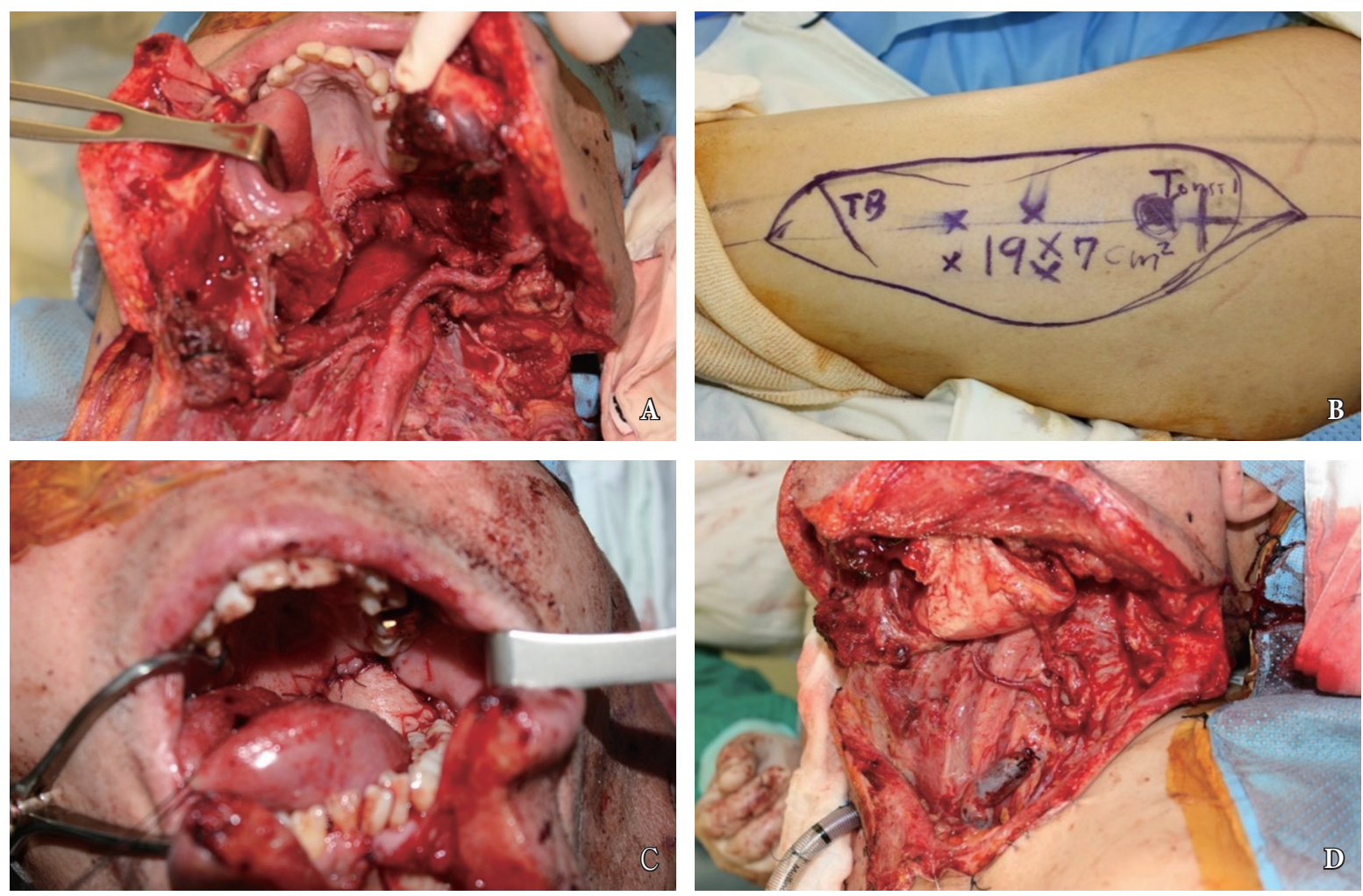

Fig. 1. Reconstruction of an extensive oral cavity defect using an anterolateral thigh free flap. (A) Intraoperative photograph after partial resection of tonsil, mouth floor, and tongue. (B) Design of the anterolateral thigh free flap. (C) Intraoral view of the reconstructed oral lining. (D) Flap pedicles in anastomosis with neck vessels.

most hospitals, with flap survival rates reported to be as high as 95\% [15-17]. Because the important functions of oral cavity and oropharynx, the purpose of reconstruction has focused on preserving such functions and helping patients to achieve a normal life (Table 1) [18-21]. Postoperative recovery of these functions is related to preservation of the anatomic structures and dimension of the oropharyngeal space [22-25]. A variety of insetting proce- dures have been developed with respect to minimizing functional deficits (e.g., folded or deepithelializing flaps). However, flap insetting remains a challenging problem for reconstruction surgeons.

\section{ANASTOMOSIS LEAK}

Despite advancements in oral reconstructive techniques, fistulas

Table 1. Comparison of the functional outcomes

\begin{tabular}{|c|c|c|c|c|c|c|}
\hline Author & Year & Journal & Scale & No. Type of flaps & $\begin{array}{l}\text { Speech } \\
\text { intelligibility (\%) }\end{array}$ & Swallowing capability (\%) \\
\hline Yanai et al. [18] & 2008 & Head Neck & $\begin{array}{l}\text { Speech: 1-5 } \\
\text { Swallowing Ability Scale System }\end{array}$ & 17 RA, rib-LD, RFFF & $\begin{array}{l}\text { Good to } \\
\text { acceptable: } 82.4\end{array}$ & Good t \\
\hline Airoldi et al. [19] & 2011 & Head Neck & $\begin{array}{l}\text { Speech: 1-7 } \\
\text { Dysphagia: 0-4 }\end{array}$ & 36 RFFF followed by RT & $72.2 \%$ Intelligible & Normal to soft diet: 77.8 \\
\hline Joo et al. [20] & 2013 & Auris Nasus Larynx & $\begin{array}{l}\text { Korean Urimal Test of } \\
\text { Articulation and Phonology }\end{array}$ & 18 RFFF & $\begin{array}{l}\text { Word: } 72.33 \\
\text { Sentence: } 61.56 \%\end{array}$ & $\begin{array}{l}\text { Normal solid: } 88.9 \% \\
\text { Pureed: } 11.1\end{array}$ \\
\hline Kekatpure et al. [21] & 2013 & Microsurgery & - & 29 ALTFF, PMMC & 72 & $\begin{array}{l}\text { Regular diet: } 20.7 \\
\text { Soft diet: } 79.3\end{array}$ \\
\hline
\end{tabular}

RA, rectus abdominis musculocutaneous free flap; rib-LD, latissimus dorsi osteomyocutaneous free flap; RFFF, radial forearm free flap; RT, radiation treatment; ALT FF, anterolateral thigh free flap; PMMC, pectoralis major musculocutaneous flap. 
around the flap margin is the most common and serious complication, occurring in $9 \%$ to $23 \%$ of cases [26]. Fistulas can further result in secondary complications such as salivary leakage, delays in postoperative chemotherapy and radiotherapy, and even carotid blowout syndrome (CBS) (Fig. 2). The latter complication, CBS, is caused by the tumor mass compromising the vascular axis or leakage of saliva, and results in rupture of the carotid artery which can lead to a lethal episode of hemorrhage. Fistulous tract from oral cavity into the connective tissue allows introduction of saliva, which is laden with bacteria and damages to the outer lining of the arterial wall [27]. The risk of anastomotic leak should be minimized with proper choice of suture material, tension-free insetting, and dead space obliteration. Fistula rates are similar in partial and circumferential reconstructions, and proximal fistulas are rare with the anterolateral flap. Incidence of fistu- la formation is higher with the radial forearm flap along the longitudinal seam of the tubed fasciocutaneous flap. Any questionable tissue should be resected until only well-vascularized tissue is observed in the proximal pharynx and cervical esophagus. The flap-to-wound margin should be closed by a single layer of simple interrupted sutures. The skin and mucosal edges should be inverted into the lumen, with suture 5-7 mm apart from each other.

\section{DONOR-SITE MORBIDITY}

Fasciocutaneous free flaps have been used for oral and oropharyngeal reconstruction since 1981 [28]. While the reconstructive features are outstanding for flaps such as forearm free flaps, donor-site morbidity remains unsatisfactory, especially when split-thickness
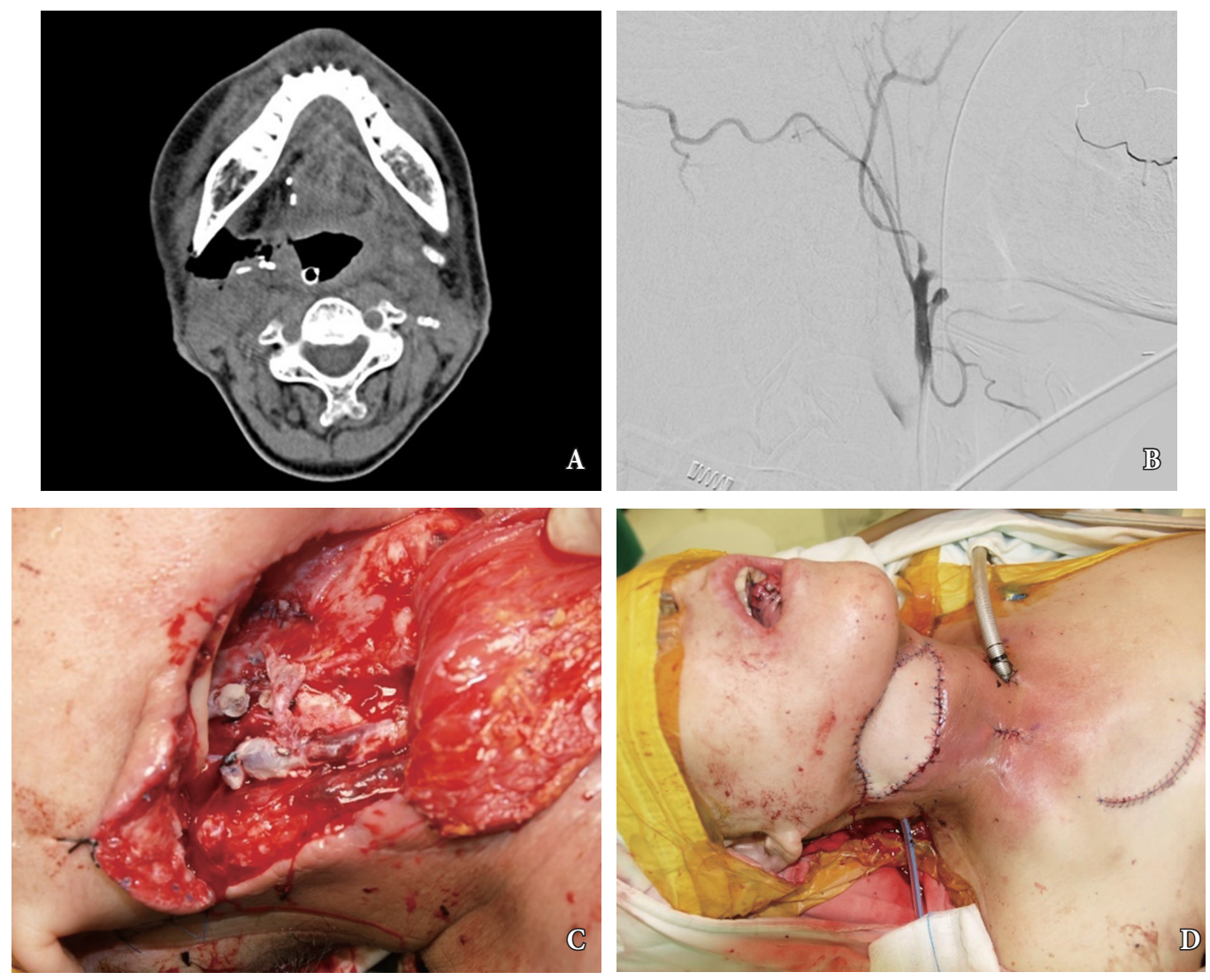

Fig. 2. Postoperative complications following free flap reconstruction of oral defect. (A) In this patient with persistent erythematous neck swelling, computed tomography scan revealed dead space in the right submandibular space, which is in continuity with the pharyngeal lumen. (B) The patient experienced a neck bleeding while under observation, and underwent emergency angiography and coiling of the external carotid artery. (C) Intraoperative view of the carotid artery, a portion of which had eroded away from saliva leak. (D) Upon control of the hemorrhagic source, the pectoralis muscle myocutaneous flap was elevated into the cervical space to obliterate the dead space and cover the external skin. 
skin graft is required [29]. Donor-site morbidity for such flaps are reported for up to $53 \%$ of cases and include tendon exposure, delayed healing, reoperation, tendon adhesion, limitation of joint movement, and poor cosmesis [30]. Changing the flap design for a proximal site along the forearm or suprafascial elevation can be useful for decreasing morbidity, donor site pain and scarring [31]. Recent studies have reported improved outcomes for donor-site morbidity by employing dermal substitutes, tissue expander, local flap with rotation, and full thickness skin grafts (Fig. 3) [32-34].

\section{CONCLUSION}

Oral and oropharyngeal cancers should be treated with consideration of functional recovery. Multidisciplinary treatment strategies are necessary for maximizing disease control and preserving
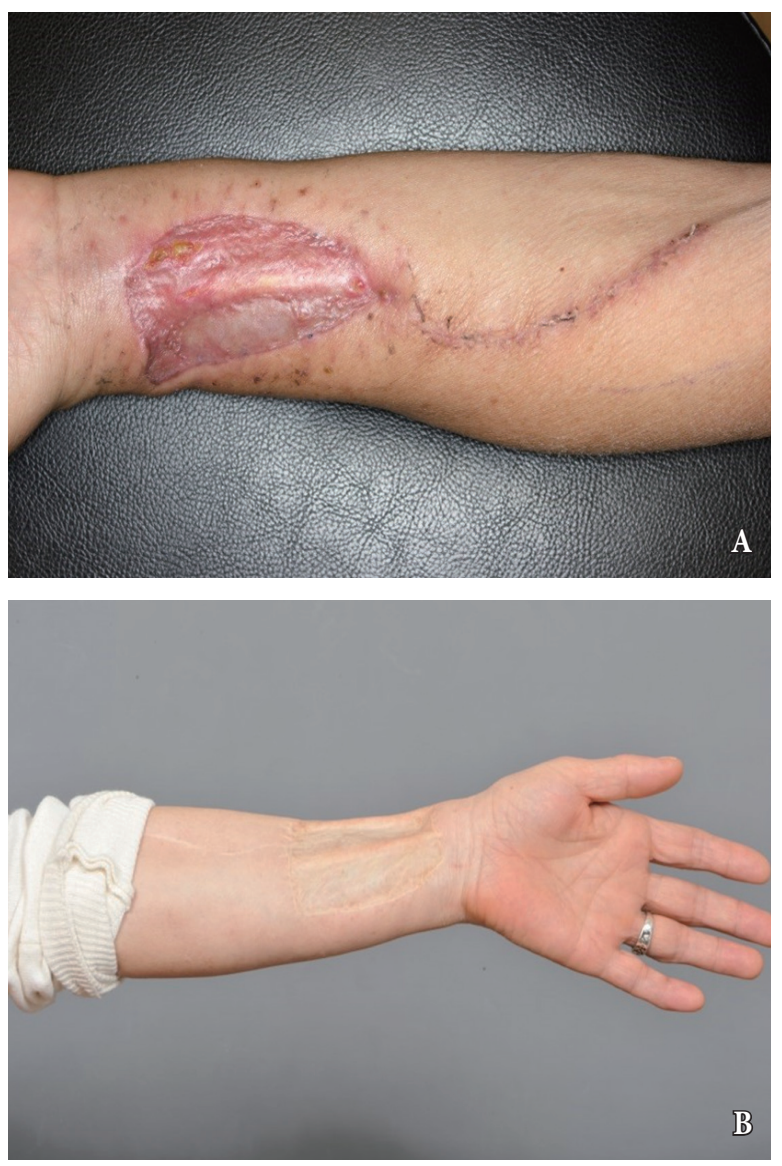

Fig. 3. Radial forearm free flap donor site. (A) This donor site was repaired with split thickness skin graft. (B) Full-thickness skin graft was used to resurface the donor site. the natural form and function of the oropharynx.

\section{REFERENCES}

1. Korean Statistical Information Service. Cancer registration statics [Internet]. Daejeon: Statistics Korea; 2014 [cited 2016 Jun 4]. Available from: http://kosis.kr/eng/statisticsList/statisticsList_01List. jsp?vwcd=MT_ETITLE\&parentId=D.

2. Huber MA, Tantiwongkosi B. Oral and oropharyngeal cancer. Med Clin North Am 2014;98:1299-321.

3. Marur S, Burtness B. Oropharyngeal squamous cell carcinoma treatment: current standards and future directions. Curr Opin Oncol 2014;26:252-8.

4. Jemal A, Bray F, Center MM, Ferlay J, Ward E, Forman D. Global cancer statistics. CA Cancer J Clin 2011;61:69-90.

5. Siegel R, Naishadham D, Jemal A. Cancer statistics, 2013. CA Cancer J Clin 2013;63:11-30.

6. Blot WJ, McLaughlin JK, Winn DM, Austin DF, Greenberg RS, Preston-Martin S, et al. Smoking and drinking in relation to oral and pharyngeal cancer. Cancer Res 1988;48:3282-7.

7. Pulte $\mathrm{D}$, Brenner $\mathrm{H}$. Changes in survival in head and neck cancers in the late 20th and early 21st century: a period analysis. Oncologist 2010;15:994-1001.

8. Pignon JP, le Maitre A, Maillard E, Bourhis J. Meta-analysis of chemotherapy in head and neck cancer (MACH-NC): an update on 93 randomised trials and 17,346 patients. Radiother Oncol 2009;92:4-14.

9. Takes RP, Rinaldo A, Silver CE, Piccirillo JF, Haigentz M Jr, Suarez C, et al. Future of the TNM classification and staging system in head and neck cancer. Head Neck 2010;32:1693-711.

10. Disa JJ, Pusic AL, Hidalgo DA, Cordeiro PG. Microvascular reconstruction of the hypopharynx: defect classification, treatment algorithm, and functional outcome based on 165 consecutive cases. Plast Reconstr Surg 2003;111:652-60.

11. Disa JJ, Pusic AL, Mehrara BJ. Reconstruction of the hypopharynx with the free jejunum transfer. J Surg Oncol 2006;94:466-70.

12. Nuara MJ, Sauder CL, Alam DS. Prospective analysis of outcomes and complications of 300 consecutive microvascular reconstructions. Arch Facial Plast Surg 2009;11:235-9.

13. Wong $\mathrm{CH}$, Wei FC. Microsurgical free flap in head and neck reconstruction. Head Neck 2010;32:1236-45.

14. Choi JW, Lee MY, Oh TS. The application of multilobed flap designs for anatomic and functional oropharyngeal reconstructions. J Craniofac Surg 2013;24:2091-7.

15. David S, Dassonville O, Poissonnet G, Chamorey E, Vallicioni J, Demard F, et al. Free-flap head and neck reconstruction failures: predictive factors and management. Ann Chir Plast Esthet 2011;56:308-14.

16. Joo YH, Sun DI, Park JO, Cho KJ, Kim MS. Risk factors of free flap compromise in 247 cases of microvascular head and neck reconstruction: a single surgeon's experience. Eur Arch Otorhinolaryngol 2010;267:1629-33. 
17. Kruse AL, Luebbers HT, Gratz KW, Obwegeser JA. Factors influencing survival of free-flap in reconstruction for cancer of the head and neck: a literature review. Microsurgery 2010;30:242-8.

18. Yanai C, Kikutani T, Adachi M, Thoren H, Suzuki M, Iizuka T. Functional outcome after total and subtotal glossectomy with free flap reconstruction. Head Neck 2008;30:909-18.

19. Airoldi M, Garzaro M, Raimondo L, Pecorari G, Giordano C, Varetto $\mathrm{A}$, et al. Functional and psychological evaluation after flap reconstruction plus radiotherapy in oral cancer. Head Neck 2011;33:458-68.

20. Joo YH, Hwang SH, Park JO, Cho KJ, Kim MS. Functional outcome after partial glossectomy with reconstruction using radial forearm free flap. Auris Nasus Larynx 2013;40:303-7.

21. Kekatpure VD, Manjula BV, Mathias S, Trivedi NP, Selvam S, Kuriakose MA. Reconstruction of large composite buccal defects using single soft tissue flap: analysis of functional outcome. Microsurgery 2013;33:184-90.

22. Denewer AD, Setit AE, Hussein OA, Aly OF. Functinal and aesthetic outcome of reconstruction of large oro-facial defects involving the lip after tumor resection. J Egypt Natl Canc Inst 2006;18:61-6.

23. Seikaly H, Rieger J, Zalmanowitz J, Tang JL, Alkahtani K, Ansari K, et al. Functional soft palate reconstruction: a comprehensive surgical approach. Head Neck 2008;30:1615-23.

24. Iseli TA, Yelverton JC, Iseli CE, Carroll WR, Magnuson JS, Rosenthal EL. Functional outcomes following secondary free flap reconstruction of the head and neck. Laryngoscope 2009;119:856-60.

25. Archontaki M, Athanasiou A, Stavrianos SD, Korkolis DP, Faratzis G, Papadopoulou F, et al. Functional results of speech and swallowing after oral microvascular free flap reconstruction. Eur Arch Otorhinolaryngol 2010;267:1771-7.
26. Andrades P, Pehler SF, Baranano CF, Magnuson JS, Carroll WR, Rosenthal EL. Fistula analysis after radial forearm free flap reconstruction of hypopharyngeal defects. Laryngoscope 2008;118:1157-63.

27. Lin YS, Wang CT, Chen YT, Chen KT. Carotid blowout syndrome. Ulus Travma Acil Cerrahi Derg 2015;21:68-70.

28. Davis WJ, 3rd, Wu C, Sieber D, Vandevender DK. A comparison of full and split thickness skin grafts in radial forearm donor sites. J Hand Microsurg 2011;3:18-24.

29. Wirthmann A, Finke JC, Giovanoli P, Lindenblatt N. Long-term follow-up of donor site morbidity after defect coverage with Integra following radial forearm flap elevation. Eur J Plast Surg 2014;37:159-66.

30. Wester JL, Pittman AL, Lindau RH, Wax MK. AlloDerm with splitthickness skin graft for coverage of the forearm free flap donor site. Otolaryngol Head Neck Surg 2014;150:47-52.

31. Toschka H, Feifel H, Erli HJ, Minkenberg R, Paar O, Riediger D. Aesthetic and functional results of harvesting radial forearm flap, especially with regard to hand function. Int J Oral Maxillofac Surg 2001;30:42-8

32. Riecke B, Assaf AT, Heiland M, Al-Dam A, Grobe A, Blessmann M, et al. Local full-thickness skin graft of the donor arm: a novel technique for the reduction of donor site morbidity in radial forearm free flap. Int J Oral Maxillofac Surg 2015;44:937-41.

33. Hanna TC, McKenzie WS, Holmes JD. Full-thickness skin graft from the neck for coverage of the radial forearm free flap donor site. J Oral Maxillofac Surg 2014;72:2054-9.

34. Jeong WS, Choi JW, Oh TS. Comparison study between coverage choices for radial forearm free flap donor site. Korean J Heak Neck Oncol 2015;31:5-8. 